\title{
PCR Detection of blaIMP Gene in Metallo- $\beta$-Lactamase Resistant $E$. coli Isolated from Clinical Samples
}

\author{
Rahul Narasanna, Siddarth Surwonse, Manjunath Chavadi and \\ Chandrakanth Kelmani*
}

Department of Biotechnology Gulbarga University Kalaburagi, India

*Corresponding author:

\section{A B S T R A C T}

\section{Keywords}

Imipenem resistant

E. coli, MBL, blaIMP

Article Info

Accepted:

20 January 2019

Available Online:

10 February 2019
PCR detection of blaIMP gene in Imipenem resistant $E$. coli is the aim ot this study. Total of $n=66$ of $n=23$ Imipenem resistant $E$. coli were selected for the present study based on the drug resistance pattern and their MIC to Imipenem. Phenotypic detection of MBL production was carried out and subsequently, PCR amplification of blaIMP was carried out. Among selected $(n=23)$ Imipenem resistant $E$. coli (IREC), 100\% $(n=23)$ strains were positive for Imipenem mediated MBL production. Twenty-three MBL positive IREC isolates were shown presence of Plasmid DNA, with size measured about approx. 6kb. PCR amplification of blaIMP gene codes for Imipenem mediated MBL production yielded amplified blaIMP gene product with amplicon size of $189 \mathrm{bp}$. The presence blaIMP gene also contributes for MBL production which makes organisms to show reduced susceptibility against Imipenem antibiotic

\section{Introduction}

$\beta$-lactam antibiotics are among the most often used antimicrobial agents and an increasing incidence of resistance to these drugs is a public health concern. $\beta$-lactam antibiotics as a class have a broad spectrum of antibacterial activity, including important Gram-positive and Gram-negative pathogens. Because of their favourable characteristics, $\beta$-lactam are the most broadly used antibiotics worldwide (Livermoore, 2006). These antibiotics act by inhibiting a set of transpeptidase enzymes (also called penicillin binding proteins or PBPs) that are essential for the synthesis of the peptidoglycan layer of the bacterial cell wall (Sauvage et al., 2008). The inhibition of peptidoglycan synthesis results in the death of growing bacteria and accounts for the antimicrobial effect of $\beta$-lactam antibiotics. In response, bacteria have evolved defence mechanisms to resist the lethal effects of these drugs (Bush et al., 2011). Due to widespread $\beta$-lactam antimicrobial use, bacterial resistance has been increasing and now represents a serious threat to the continued use of antibiotic therapy (Babic et al., 2006).

Site directed mutagenesis studies of the active site histidines in MBLs have been performed 
and the results are consistent with an important role for these residues in zinc binding and hydrolytic activity (Haruta et al., 2000). Saturation mutagenesis and directed evolution studies of MBLs have also yielded insights into the sequence requirements for enzyme function. Materon et al., analysed the residues in and near the active site of the subclass B1 IMP-1 enzyme using a randomization and genetic selection strategy (Materon et al., 2004). For these studies, the codons for 29 residue positions in IMP-1 were individually randomized by oligonucleotide mutagenesis to create 29 random libraries. Each random library was then introduced into $E$. coli and clones expressing functional $\beta$ lactamase mutants were identified by selection for growth on agar plates containing $\beta$-lactam antibiotic

The recently discovered NDM-1 $\beta$-lactamase provides an example of the potential for dissemination of MBLs. NDM-1 was first detected in 2008 in K. pneumonia and E. coli in a patient returning to Sweden from India. NDM-1 has been shown to be present at significant frequency within Enterobacteriaceae in India and has subsequently been shown to be present in bacterial isolates in a number of countries worldwide. The $b l a_{\mathrm{NDM}-1}$ gene has been found on several plasmid types, including IncA/C, IncF, IncL/M, and it can be transferred among gram negative bacteria by conjugation. However, in contrast to the situation with the genes encoding IMP- and VIM-type MBLs, the bla $_{\mathrm{NDM}-1}$ gene has not been found in integrons structures. Nevertheless, NDM-1 has spread broadly and rapidly (Nordmann et al., 2011). The ISAba125 insertion element has been associated with the bla $a_{\mathrm{NDM}-1}$ gene suggesting insertion sequences may contribute transfer of NDM-1. Therefore, the principal objective of this study was to investigate the presence of blaIMP gene and associated plasmids from these E. coli clinical isolates.

\section{Materials and Methods}

\section{Bacterial isolates}

The total of $\mathrm{n}=23$ Imipenem resistant $E$. coli were selected for the present study. Identification was done based on culture characteristics. The antimicrobial susceptibility test was carried out as per CLSI standards for determination of drug resistance, further MIC of imipenem was also carried out. Based on that the isolates were selected for further study. All strains were cultured in Luria-Bertani (LB) broth and stored in cryovials with $30 \%$ glycerol at $-20^{\circ} \mathrm{C}$.

\section{MBL - Metallo - $\beta$-lactamases}

\section{Phenotypic detection of MBLs}

The phenotypic detection method of MBL production was designed using a single agar plate and consist of two components (i) In the combined-disk test, two IPM disks $(10 \mu \mathrm{g})$, one containing $10 \mu \mathrm{l}$ of $0.1 \mathrm{M}(292 \mu \mathrm{g})$ anhydrous EDTA (Sigma Chemicals, St. Louis, MO), were placed $25 \mathrm{~mm}$ apart. An increase in zone diameter of $>4 \mathrm{~mm}$ around the IPM-EDTA disk compared to that of the IPM disk alone was considered positive for an MBL, (ii) In the DDST, an IPM (10 $\mu \mathrm{g})$ disk was placed $20 \mathrm{~mm}$ from a blank disk containing $10 \mu \mathrm{l}$ of $0.1 \mathrm{M}(292 \mu \mathrm{g})$ EDTA. Enhancement of the zone of inhibition in the area between the two disks was considered positive for an MBL. Disks were applied to the surface of the inoculated agar as shown in and plates were incubated overnight at $37^{\circ} \mathrm{C}$ (Drieux et al., 2008; Chauhan et al., 2015).

\section{DNA extraction}

Plasmid DNA was extracted from bacterial isolates by alkaline lysis method. The DNA bands were observed on agarose gel 
electrophoresis under UV-transilluminator. The extracted DNA was stored at $-20^{\circ} \mathrm{C}$ in TE buffer (Sambrook et al., 2009).

\section{PCR amplification of metallo-ß-lactamase coding genes}

PCR amplification was performed to detect plasmid-encoded bla-IMP responsible for metallo- $\beta$-lactamase production. Primers, sourced from Chromous Biotech Pvt Ltd, Bangalore, were for blaIMP-5, GGAATAGAGTGGCTTAACTCTC 3' (Forward), blaIMP (reverse) 5, CCAAACTACTAGGTTATCT - 3' (Fallah et al., 2013). For PCR amplification, about $100 \mathrm{ng}$ of DNA was added to $50 \mu 1$ mixture containing $2.5 \mathrm{mM}$ of dNTPs, $0.5 \mathrm{mM}$ of each forward and reverse primer and $3 \mathrm{U}$ of $\mathrm{Taq}$ polymerase in 10x PCR buffer containing 1.5 $\mathrm{mM} \mathrm{MgCl} 2$. Amplification was performed in a Corbett CGI-96 Thermocycler with cycling parameters comprising initial denaturation at $94^{\circ} \mathrm{C}$ for $5 \mathrm{~min}$ each followed by 35 cycles of denaturation at $94^{\circ} \mathrm{C}$ for $30 \mathrm{~s}$, annealing at $55^{\circ} \mathrm{C}$ for $30 \mathrm{~s}$, extension at $72^{\circ} \mathrm{C}$ for $30 \mathrm{sec}$ and final extension at $72^{\circ} \mathrm{C}$ for $7 \mathrm{~min}$. A 100 bp DNA ladder and 500 bp DNA ladder (Bangalore Genei Pvt Limited, India) were used to measure the size of amplicons.

\section{Results and Discussion}

\section{Selection of bacterial strains}

The total of $\mathrm{n}=23$; Metallo- $\beta$-Lactamase producing E. coli were selected for the present study after antimicrobial susceptibility test and MIC to Imipenem. Among selected $(\mathrm{n}=23)$ Imipenem resistant E. coli (IREC). The marginal increase in zone of inhibition by $>5 \mathrm{~mm}$ of Imipenem/ EDTA combination in comparison with Imipenem alone (Fig 1). Among $\mathrm{n}=23 \mathrm{E}$. coli isolates, all of them were positive for metallo-ß-lactamase production. This was phenotypically confirmed by MBL phenotypic detection method. Twenty-three $E$. coli isolates were positive MBL producers.

\section{PCR detection of blaIMP gene}

All the $n=23$ MBL producing MDR E. coli strains have been selected for genotypic study, i.e., PCR amplification of MBL producing genes, blaIMP ((accession no. MF169878). The samples showed amplification of $189 \mathrm{bp}$ (Fig. 2), with primers specific to blaIMP. The BLAST analysis of the respective sequences was matching 100\% blaIMP.

The increasing incidence of MBL producing Enterobacteriaceae, particularly E. coli and $K$. pneumoniae posing a serious threat to public health across the world. The present study $n=23 E$. coli isolates, all of them were positive for metallo-ß-lactamase production. This was phenotypically confirmed by MBL phenotypic detection method. Twenty-three $E$. coli isolates were positive MBL producers.

Earlier studies indicated a high incidence of MBL producing E. coli $(18.98 \%)$ in different clinical samples. A previous study from an another tertiary care hospital in Nepal reported comparatively lower incidence of MBL producing gram negative bacteria $(1.3 \%)$ in lower respiratory tract specimens (Mishra et al., 2012).

The majority of MBL producing isolates of $E$. coli $(53.56 \%)$ were from patients admitted to ICU. The ICU has been described as a factory for creating, disseminating, and amplifying antimicrobial resistance (Bora et al., 2014).

MBL producing bacterial isolates can confer resistance to carbapenems and all beta-lactam agents except aztreonam although coexistence of other resistance mechanisms such as AmpC type beta-lactamases or ESBLs render them resistant to aztreonam (Bora et al., 
2014). Likewise, all the isolates of E. coli and $K$. pneumoniae with MBL production in the present study were found to be resistant to carbapenems. These isolates also exhibited a high level of resistance to the penicillin's, the third and fourth generation cephalosporin as well as to the beta-lactam/beta-lactamase inhibitor combination tested in the study.
These findings are similar with other reports (Johnson et al, 2010: Deshmukh et al., 2014), whereas in few reports MBL producing enterobacteriaceae isolates were found to be susceptible to various carbapenems as well as to piperacillin/tazobactam by disc diffusion testing (Seema et al., 2011).

Fig.1 The increase in the zone of inhibition with an IPM $(10 \mu \mathrm{g})$ disk plus $292 \mu \mathrm{g}$ EDTA could increase the zone diameter by up to $4 \mathrm{~mm}$ compared to that of an IPM disk alone

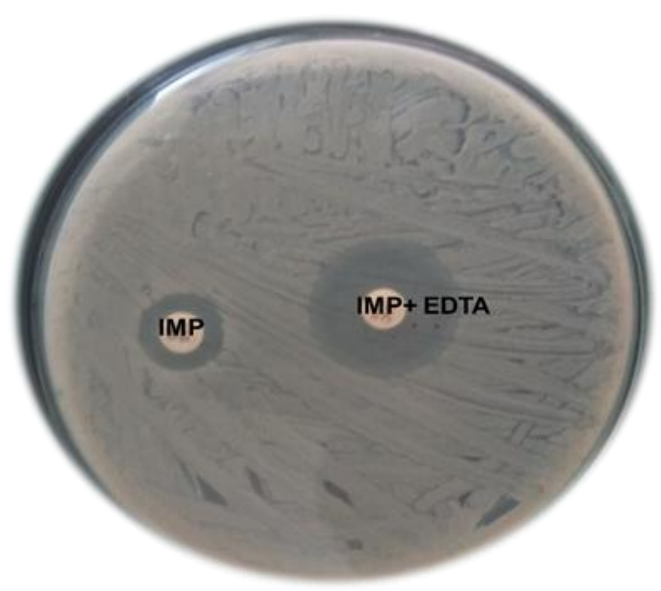

Fig.2 blaIMP gene with amplicon size of 189 bp

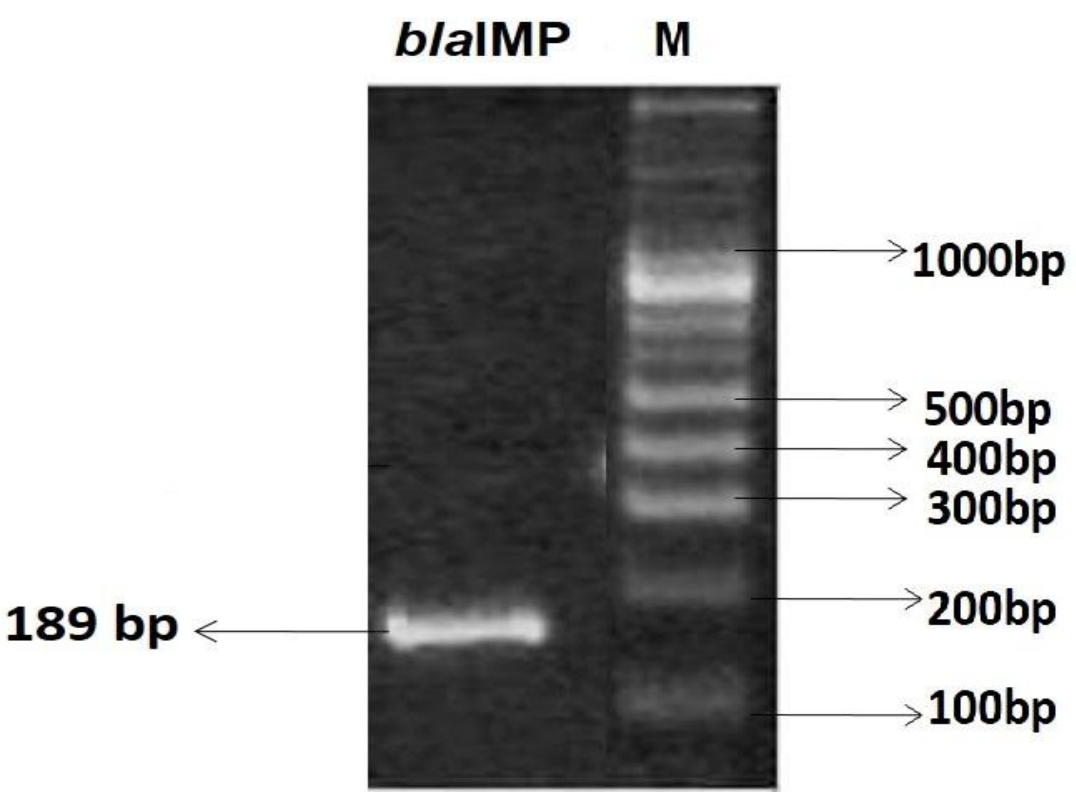

Lane $1-\mathrm{M}(100 \mathrm{bp}$ ladder) ranging from 100bp - 1kb 
All the $23 \mathrm{MBL}$ producing MDR E. coli strains have been selected for genotypic study, i.e., PCR amplification of MBL producing gene blaIMP. The samples showed amplification of 189 bp (Fig. 2), with primers specific to blaIMP.

Since 1988, transferable carbapenem resistance has been found in several $P$. aeruginosa strains isolated in Toyama Prefecture, Japan (Lagatolla et al., 2004). In 1991, an IMP-1 type MBL, initially characterized in a strain of $S$. marcescens, gave high-level resistance to various broadspectrum $\beta$-lactams including imipenem (Ito et al., 1995). This strain was isolated in a hospital in Aichi Prefecture and had the intII gene just upstream of the bla IMP-1 $_{1}$ gene cassette on the chromosome.

It was confirmed that the IMP-1 type of MBL is the most common MBL in Japan at present, although IMP-3 (Iyobe et al., 2000) and IMP6 (Shigemoto et al., 2010) have also been identified in Japan. Since very few amino acid substitutions exist among IMP-1, IMP-3, and IMP-6, the latter two MBLs are fundamentally variants of IMP-1. It is difficult to confirm whether all the $b l a_{\mathrm{IMP}-1^{-}}$ positive strains found in this study carry genuine $b l a_{\mathrm{IMP}-1}$, since the primer sets used in this study cannot distinguish $b l a_{\mathrm{IMP}-3}$ and bla $_{\mathrm{IMP}-6}$ from bla $_{\mathrm{IMP}-1}$

\section{References}

Babic, M., Hujer, A. M., and Bonomo, R. A. (2006). What's new in antibiotic resistance? Focus on beta-lactamases. Drug resistance updates, 9(3), 142-156.

Bora, A., Sanjana, R., Jha, B. K., Mahaseth, S. N., and Pokharel, K. (2014). Incidence of metallo-beta-lactamase producing clinical isolates of Escherichia coli and Klebsiella pneumoniaea in central Nepal. $B M C$ research notes, $7(1), 557$.

Bush, K., and Fisher, J. F. (2011). Epidemiological expansion, structural studies, and clinical challenges of new $\beta$-lactamases from gram-negative bacteria. Annual review of microbiology, 65, 455-478.

Chauhan, K., Pandey, A., Asthana, A. K., and Madan, M. (2015). Evaluation of phenotypic tests for detection of Klebsiella pneumoniaea carbapenemase and metallo-beta-lactamase in clinical isolates of Escherichia coli and Klebsiella species. Indian Journal of Pathology and Microbiology, 58(1), 31.

Deshmukh, H. S., Liu, Y., Menkiti, O. R., Mei, J., Dai, N., O'leary, C. E. and Worthen, G. S. (2014). The microbiota regulates neutrophil homeostasis and host resistance to Escherichia coli $\mathrm{K} 1$ sepsis in neonatal mice. Nature medicine, 20(5), 524.

Drieux, L., Brossier, F., Sougakoff, W., and Jarlier, V. (2008). Phenotypic detection of extended-spectrum $\beta$-lactamase production in Enterobacteriaceae: review and bench guide. Clinical Microbiology and Infection, 14, 90-103.

Fallah, F., Borhan, R. S., and Hashemi, A. (2013). Detection of bla (IMP) and bla (VIM) metallo- $\beta$-lactamases genes among Pseudomonas aeruginosa strains. International journal of burns and trauma, 3(2), 122.

Haruta, S., Yamaguchi, H., Yamamoto, E. T., Eriguchi, Y., Nukaga, M., O'Hara, K., and Sawai, T. (2000). Functional analysis of the active site of a metallo$\beta$-lactamase proliferating in Japan. Antimicrobial agents and chemotherapy, 44(9), 2304-2309.

Ito, H., Arakawa, Y., Ohsuka, S., Wacharotayankun, R., Kato, N., and Ohta, M. (1995). Plasmid-mediated dissemination of the metallo-beta- 
lactamase gene blaIMP among clinically isolated strains of Serratia marcescens. Antimicrobial agents and chemotherapy, 39(4), 824-829.

Iyobe, S., Kusadokoro, H., Ozaki, J., Matsumura, N., Minami, S., Haruta, S.,... and O'Hara, K. (2000). Amino acid substitutions in a variant of IMP-1 metallo- $\beta$-lactamase. Antimicrobial agents and chemotherapy, 44(8), 20232027.

Johnson, J. R., Johnston, B., Clabots, C., Kuskowski, M. A., and Castanheira, M. (2010). Escherichia coli sequence type ST131 as the major cause of serious multidrug-resistant $E$. coli infections in the United States. Clinical infectious diseases, 51(3), 286-294.

Lagatolla, C., Tonin, E. A., Monti-Bragadin, C., Dolzani, L., Gombac, F., Bearzi, C.,.and Rossolini, G. M. (2004). Endemic carbapenem-resistant Pseudomonas aeruginosa with acquired metallo- $\beta$-lactamase determinants in European hospital. Emerging infectious diseases, 10(3), 535.

Livermore, D. M., Woodford, N., Ellington, M. J., Coelho, J. M., Turton, J. F., Ward, M. E., Brown, S., (2006). Multiplex PCR for genes encoding prevalent OXA carbapenemases in Acinetobacter spp. International journal of antimicrobial agents, 27(4), 351-353

Materon, I. C., Beharry, Z., Huang, W., Perez, C., and Palzkill, T. (2004). Analysis of the context dependent sequence requirements of active site residues in the metallo- $\beta$-lactamase IMP-1. Journal of molecular biology, 344(3), 653-663.

Nordmann, P., Poirel, L., Walsh, T. R., and Livermore, D. M. (2011). The emerging NDM carbapenemases. Trends in microbiology, 19(12), 588-595.

Sambrook, J., Fritsch, E.F., dan Maniatis, T. 1989. molecular cloning a laboratory manual, 2nd edition. New York: Cold Spring Harbor Laboratory Press.

Sauvage, E., Kerff, F., Terrak, M., Ayala, J. A., and Charlier, P. (2008). The penicillin-binding proteins: structure and role in peptidoglycan biosynthesis. FEMS microbiology reviews, 32(2), 234-258.

Seema, K., Ranjan Sen, M., Upadhyay, S., and Bhattacharjee, A. (2011). Dissemination of the New Delhi metallo- $\beta$-lactamase-1 (NDM-1) among Enterobacteriaceae in a tertiary referral hospital in north India. Journal of antimicrobial chemotherapy, 66(7), 1646-1647.

Shigemoto, N., Kuwahara, R., Kayama, S., Shimizu, W., Onodera, M., Yokozaki, M. and Sugai, M. (2012). Emergence in Japan of an imipenem-susceptible, meropenem-resistant Klebsiella pneumoniae carrying blaIMP-6. Diagnostic microbiology and infectious disease, 72(1), 109-112.

\section{How to cite this article:}

Rahul Narasanna, Siddarth Surwonse, Manjunath Chavadi and Chandrakanth Kelmani. 2019. PCR Detection of blaIMP Gene in Metallo- $\beta$-Lactamase Resistant E. coli Isolated from Clinical Samples. Int.J.Curr.Microbiol.App.Sci. 8(02): 2696-2701. doi: https://doi.org/10.20546/ijcmas.2019.802.315 